\title{
Skindex-29 to Determine Quality of Life and Emotional Factors in Dermatological Conditions
}

\author{
Desiree Saimbi , MSVK Raju', Vaibhav Dubey', Vivek Kumar Dey ${ }^{2}$ \\ Department of Psychiatry ${ }^{1}$, Dermatology ${ }^{2}$, Venereology and Leprology \\ People's College of Medical Science, Bhopal.
}

\begin{abstract}
Though rarely fatal, skin diseases are known to be associated with increased psychiatric morbidity and considerable impairment of quality of life (QoL). Health Related Quality of Life (HRQoL) in skin diseases can be assessed by generic or skin specific instruments. One hundred sixty patients with a range of dermatological diagnoses were studied on a cross sectional observational paradigm. Skindex29, a skin specific instrument, was used to assess QoL, while anxiety and depression were assessed by Anxiety Status Inventory (ASI) and Depression Status Inventory (DSI), respectively. Sixty two patients $(39 \%)$ had impaired QoL out of which $37(60 \%)$ had severe impairment. 11 patients $(7 \%)$ had anxiety and 22(14\%) had depression in the mild to moderate range. Gender, anxiety, depression and effect on appearance seem to be not related to impaired QoL. Further large scale studies are needed to ascertain the factors impinging on the QoL of dermatologically ill patients.
\end{abstract}

Keywords: Quality of life, anxiety, depression, skindex-29, skin diseases.

Correspondence : Dr. Desiree Saimbi, Department of Psychiatry, People's College of Medical Sciences, Bhopal (M.P). Mob : 7354547713.E-mail: dsaimbi@gmail.com.

DR. S. S. MISRA MEMORIAL AWARD delivered during NAMSCON 2014 at the All India Institute of Medical Sciences, Rishikesh. 


\section{Introduction}

Skin gets frequently damaged because it is directly in the 'firing line'. The 3000 and odd known diseases of skin form the most common health problems afflicting people worldwide (1). Some of these conditions are among the top ten leading causes of non-fatal disease burden (2). Though rarely life threatening, the effects of cutaneous disorders on patients' lives can be profound as in addition to the distress brought about by symptoms and lesions, they affect interpersonal interactions as the lesions as well as the treatment thereof affect the appearance of individuals (3). Prevalence of psychiatric disorders in dermatological patients is higher than that of certain medical conditions like cancer, cardiac and neurological disorders (4) but remain unrecognized and underestimated (5, $6)$. The interrelationships between skin and psychiatric disorders can be quite complex: Social isolation and stigma associated with skin conditions may result in psychiatric illnesses; poor hygiene in chronic psychiatric disorders can cause skin problems; psychiatric disorders may present as dermatological problems, ( De lusional parasitosis, body dysmorphophobia) certain drugs used in dermatology may have secondary psychiatric problems and vice versa; psychiatric disorders may aggravate skin conditions and also may lead to poor help seeking behavior (7-9). Psychiatric morbidity in skin diseases therefore may adversely affect quality of life (QoL) in many ways.

Health-related quality of life (HRQoL), defined as the patients subjective evaluation of the influences of their current health status on their ability to achieve and maintain a level of overall functioning that allow them to achieve valued life goals and that are reflected in their general wellbeing (10), is considered as an essential outcome measure in addition to clinical parameters in skin diseases $(11,12)$. Upto a third of persons with skin diseases are known to suffer from psychopathology mainly in the form of anxiety and depression (13-16) but due to shortfall of required skills dermatologist's assessment of mental status of patients is known to be sensitive at $30 \%$ only (5) which underscores the importance of collaborative management of patients by dermatologists as well as psychiatrists. However, it would be wrong to assume that QoL is totally linked to psychiatric morbidity (17).

Psychiatric morbidity and HRQoL are fairly well investigated in specific dermatological conditions like Psoriasis (18, 19), Vitiligo (20, 21), Acne (22, 23), Alopecia (24, 25), Eczema (26) and Hansen's disease (27). There are just a few studies which investigated psychiatric morbidity and HRQoL in dermatological patients in general $(8,28-30)$. Somehow this field did not appear to have attracted investigators from India; two recent reviews from India hardly had any references of Indian studies $(4,17)$.

\section{Material and Method}

The study was conducted at a hospital attached to a medical college in central India on a cross sectional observational design. One hundred and sixty patients were selected at random from in-patient and outpatient population of the dermatology department. All the patients who were above 18 years of age and those who were willing to participate in the study only were accepted. Patients suffering from major medical illnesses, psychoses and significant cognitive impairments were excluded from the study. All the patients were furnished with written information about the nature of the study. The study was approved by the research and ethics committee of the institution.

All the skin diagnoses were made by dermatologists. Every patient was subjected to standard mental status examination. The following instruments were used to measure anxiety, depression and QoL: 
Anxiety Status Inventory (ASI): This is a structured interview version of Zung's selfrating anxiety scale (31). 20 affective and somatic symptoms associated with anxiety are rated on a 4 point Likert scale (none, mild, moderate and severe). Maximum score is 80 . Obtained score is converted into an index and graded into mild, moderate and severe. The test was translated into vernacular Hindi by translation and back translation by different experts and administered to 50 bilinguals. The correlation between English and Hindi version was found to good $(r=0.76, p<0.001)$. The Hindi version was utilized for the study.

Depression Status Inventory (DSI): This is a structured interview version of the Zung Self Rating Depression Scale (32). There are 20 items in this scale that explore the affective, psychological and somatic symptoms associated with depression. Each question is scored on a scale of 1 to 4 . Maximum possible score is 80 . Procedure similar to anxiety inventory was adapted to obtain Hindi version and correlation was found to be $\operatorname{good}(\mathrm{r}=0.79, \mathrm{p}<0.01)$. Obtained score in a given individual is converted into an index and graded into mild, moderate and severe grades.

Skindex-29: This is a skin specific QoL instrument devised by Chren (33). It has 30 items distributed into domains (symptoms, function and emotion). Each of the items is scaled on a 5 point Likert scale. All the responses are transferred to a linear scale (Never $=0$, rarely $=25$, sometimes $=50$, often $=75$ and all the time $=100$ ). Domain and overall scores can be computed. Overall score is the mean of the responses. Item number 18 is excluded from scoring as per the guidelines of the originators of the test. This test was also subjected to translation and back translation. Hindi version was found to be well correlated to the original English version ( $r=0.86, p<0.001)$. QoL scores were graded into mild, moderate and severe grades as per Prinsen et al (34).
Statistical Analysis: Depression and anxiety scores were correlated with overall Skindex-29 scores by means of Pearson's product moment correlation test. Mean anxiety and depression scores of each grade of Skindex-29 were compared by means of one-way ANOVA followed by post hoc Tukey's test. One-way ANOVA was also used to compare the anxiety, depression and QoL scores in relation to symptom and diagnostic categories. Student's t-test was used to compare the anxiety, depression and Skindex-29 scores between genders. Domain scores were not subjected to analysis in this study.

\section{Results}

A total of 62 patients (39\%) had impaired QoL out of which 15 had mild, 10 had moderate and 37 had severe grades impairments. Ninty eight patients reported no impairment in their QoL. Twenty two patients (14\%) had depression while $11(7 \%)$ had anxiety. Mean overall Skindex score was $25.27 \pm 20.21 \quad($ Mean \pm SD) while that of anxiety and depression was $32.3 \pm 8.43$ and $39 \pm 8.4$, respectively. There was no significant difference ( $\mathrm{t} 0.39, \mathrm{p}<0.05$ ) between Skindex scores of males $(26.1 \pm 20.38)$ and females $(24.51 \pm 20.22)$. No significant difference was also found in the anxiety (t 0.37 , $\mathrm{p}<0.05$ ), depression ( $\mathrm{t} 0.12, \mathrm{p}<0.05$ ) between genders. Overall Skindex-29 scores were found to be highly correlated to ASI $(r=0.29, \mathrm{p}<0.001)$ and DSI scores $(r=0.37, p<0.001)$. We categorized patients into seven groups based on the predominant symptoms that they had, and compared their anxiety, depression and Skindex29 scores. No significant differences in anxiety (F 1.09, $p>0.05$ ) depression (F 0.71, p >0.05) and Skindex scores ( F 1.22, $\mathrm{p}>0.05$ ) were found between patients with different symptoms (Table 1). ANOVA revealed uniform distribution of anxiety ( $\mathrm{F} 1.69, \mathrm{p}>0.05)$ and depression ( $\mathrm{F} 1.02, \mathrm{p}>0.05$ ) scores across diagnostic categories. However, Skindex-29 scores were found to be differentially distributed ( F 2.69, $\mathrm{p}<0.007$ ) in various diagnoses: scabies patients had the lowest score (mean 13.8, SD 
Table 1: Anxiety, Depression, Skindex-29 QoL scores in-relation to Symptoms

\begin{tabular}{lccl}
\hline Symptoms & Anxiety & Depression & Skindex-29 \\
\hline Eruptions & 26.6 & 31.6 & 24.9 \\
$(\mathbf{n = 4 5})$ & $(7.4)$ & $(6.2)$ & $(18.5)$ \\
Erythema & 27.1 & 33.4 & 27 \\
$(\mathbf{n = 3 7 )}$ & $(9.1)$ & $(9.5)$ & $(17.1)$ \\
Hyperpigmentation & 26.7 & 31.8 & 24.3 \\
$(\mathbf{n = 3 2})$ & $(8.2)$ & $(6.5)$ & $(21.1)$ \\
Hypopigmentation & 25.3 & 30.6 & 22.1 \\
$(\mathbf{n = 2 0})$ & $(7.2)$ & $(5.9)$ & $(18)$ \\
Itching & 21.8 & 29.3 & $(17)$ \\
$(\mathbf{n = 1 3 )}$ & $(2.1)$ & $(1.8)$ & 45.2 \\
Impaired Sensation & 30.4 & 31.8 & $(22)$ \\
$(\mathbf{n}=\mathbf{5})$ & $(9.4)$ & $(3.3)$ & $(1.8)$ \\
Alopecia & 23 & 30 & \\
(n=8) & $(4.85)$ & $(20)$ & \\
\hline ANOVA Anxiety & $\mathrm{F}=1.09 \quad \mathrm{Df}=6,153$ & $\mathrm{P}=0.366$ & \\
ANOVA Depression & $\mathrm{F}=0.71 \quad \mathrm{Df}=6,153$ & $\mathrm{P}=0.642$ & \\
ANOVA QOL & $\mathrm{F}=1.22 \quad \mathrm{Df}=6,153$ & $\mathrm{P}=0.298$ &
\end{tabular}

Table 2 : Anxiety, Depression, Skindex-29 QoL scores in-relation to Diagnosis

\begin{tabular}{lllll}
\hline Diagnosis & $\mathbf{N}$ & Anxiety & Depression & Skindex-29 \\
\hline Acne & 38 & 29.9 & 32.2 & 26 \\
& $(23.7)$ & $(8.2)$ & $(7.1)$ & $(20.2)$ \\
Eczema & 29 & 25.8 & 32.3 & 33 \\
& $(18.1)$ & $(6.2)$ & $(5.6)$ & $(19.8)$ \\
Tinea & 27 & 28.4 & 32.6 & 27.6 \\
& $(16.8)$ & $(7.3)$ & $(3.5)$ & $(20.1)$ \\
Hansen & 4 & 31.2 & 32 & 45.8 \\
disease & $(2.5)$ & $(10.9)$ & $(3.8)$ & $(25)$ \\
Psoriasis & 17 & 30.7 & 34.6 & 38 \\
& $(10.6)$ & $(13.9)$ & $(13)$ & $(21.1)$ \\
Scabies & 20 & 23 & 30 & 13.8 \\
& $(12.5)$ & $(3.2)$ & $(2.3)$ & $(9.9)$ \\
Vitiligo & 6 & 22.1 & 26.1 & 16.1 \\
& $(3.75)$ & $(3.4)$ & $(4.3)$ & $(4.2)$ \\
Alopecia & 8 & 23 & 30 & 29.8 \\
& $(5)$ & $(4.8)$ & $(2)$ & $(1.8)$ \\
Urticaria & 11 & 22.3 & 30.4 & 21.7 \\
& $(6.8)$ & $(3.4)$ & $(4.1)$ & $(16)$ \\
\hline
\end{tabular}

$\begin{array}{llll}\text { ANOVA Anxiety } & \mathrm{F}=1.69 & \mathrm{Df}=8,151 & \mathrm{P}=0.099 \mathrm{NS} \\ \text { ANOVA Depression } & \mathrm{F}=1.02 & \mathrm{Df}=8,151 & \mathrm{P}=0.429 \mathrm{NS} \\ \text { ANOVA QOL } & \mathrm{F}=2.69 & \mathrm{Df}=8,151 & \mathrm{P}=0.007 \text { (Sig.) }\end{array}$


Table 3 : Skindex vs ASI

\begin{tabular}{lllll}
\hline & $\begin{array}{l}\text { Normal } \\
(\mathbf{N}=98)\end{array}$ & $\begin{array}{l}\text { Mild } \\
(\mathbf{N}=\mathbf{1 5})\end{array}$ & $\begin{array}{l}\text { Moderate } \\
\mathbf{( N = 1 0 )}\end{array}$ & $\begin{array}{l}\text { Severe } \\
\mathbf{( N = 3 7 )}\end{array}$ \\
\hline Mean & 28.1 & 31.5 & 32.8 & 38.4 \\
SD & 7.9 & 5.7 & 8.7 & 14.3 \\
\hline
\end{tabular}

F:4.69

$\mathrm{P}<0.05$

Df: 3,156

Tukeys Test

Normal vs mild

Mild vs moderate

$\mathrm{t}=1.11$

$\mathrm{t}=0.15$

$\mathrm{P}>0.05$ (NS)

Moderate vs severe
$\mathrm{P}>0.05(\mathrm{NS})$

$\mathrm{P}>0.05$ (NS)
9.8) while people with Hansen's disease had the highest impairment (mean 45.8, SD 25.0) (Table 2). Anxiety scores of patients with various grades of impairment of QoL though found to be non-homogenous ( F 4.69, $\mathrm{p}<0.05$ ) but multiple comparisons by Tukey's test revealed no significant differences (Table 3). Depression scores of patients with different grades of QoL impairments were also found to be not uniform (F 4.37, p <0.05) but post hoc analysis by Tukey's test revealed no significant differences (Table 4).

\section{Discussion}

The interaction of dermatological conditions on the psychosocial aspects of existence can be quite complex with matters impinging on such issues as satisfaction with appearance, body image, identity, socialization and sexuality with potential for restricted social interactions, reduced opportunities for employment $(35,29)$ and the obvious threat of, and sometimes actual, diminished opportunities for interpersonal attraction, friendship and mate selection. Clinicians routinely interpret measurements of physical functioning clinically and by investigations. Interpretations of the findings, in most medical illnesses, is fairly simple as they are compared against norms but in cases of skin disease due to intervening emotional factors, patient's experience with illnesses becomes a crucial factor in determining effectiveness of treatment (11). Suffering could be unique in many ways in skin conditions.

We attempted to assess QoL in a large sample of dermatologically ill by means of Skindex-29 which is considered to be an ideal tool for such an investigation (36). We analyzed only the overall scores in the present paper. We also attempted to find if the grades of severity of HRQoL correspond in any way to the grades of anxiety and depression measured by standard instruments. We believe this is the first time that such an investigation was carried out in India.

In the present study, we found more than a third of patients had reported impaired QoL, majority $(60 \%)$ of which to a severe degree. HRQoL is a subjective estimate. Wide variations in scores are therefore possible as disease perceptions may vary from individual to individual and culture to culture. Skindex-29 scores ranging from 20 to 78 have been reported in literature $(18,29,37-39)$. 
Table 4 : Skindex vs DSI

\begin{tabular}{lllcc}
\hline & $\begin{array}{l}\text { Normal } \\
(\mathbf{N = 9 8 )}\end{array}$ & $\begin{array}{l}\text { Mild } \\
(\mathbf{N = 1 5 )}\end{array}$ & $\begin{array}{l}\text { Moderate } \\
(\mathbf{N = 1 0})\end{array}$ & $\begin{array}{l}\text { Severe } \\
(\mathbf{N = 3 7 )}\end{array}$ \\
\hline Mean & 36.5 & 39.0 & 39.5 & 43.9 \\
SD & 5.7 & 5.8 & 12.3 & 12.2 \\
\hline
\end{tabular}
F: 4.37
$\mathrm{P}<0.05$
Df: 3,156

Tukeys Test

$\begin{array}{lll}\text { Normal vs mild } & \mathrm{t}=1.27 & \mathrm{P}>0.05(\mathrm{NS}) \\ \text { Mild vs moderate } & \mathrm{t}=0.33 & \mathrm{P}>0.05(\mathrm{NS}) \\ \text { Moderate vs severe } & \mathrm{t}=1.62 & \mathrm{P}>0.05(\mathrm{NS})\end{array}$

The widely dispersed scores indicate differential effects but were not related to symptoms which we find somewhat counterintuitive as we imagined symptoms like pain, lack of pain, hyperpigmentation and hypopigmentation eruptions and so on will have different implications for the patients. Patients with different symptoms appear to be uniformly distressed (Table 1). The diagnostic label of the disease and chronicity seem to be significant determining factors as we found conditions like Hansens and psoriasis are associated with poor QoL in contrast to scabies, findings are in agreement with Kosaraju et al (40), Sanclemente et al (41). Effect of the disease lesions on appearance do not seem to be affecting the QoL much as we find obviously visible conditions like acne, vitiligo, tinea and urticaria are associated with fairly good QoL (Table 2). This finding, once again, is contrary to what is expected; perhaps analysis of domain scores will throw some light on this phenomenon.

In the present study, the prevalence of anxiety was found to be much less than that reported by Seyhan et al (8) (13.4\%), Kumar et al (19) (52\%), Jindal et al (42) (11.28\%) and Aslam et al (43) (20\%), Abebe et al (44) $(37.4 \%)$. It is to be noted that they investigated individual skin conditions. Our study sample included all major and minor conditions hence it is possible the prevalence figures are getting averaged. We found significant correlation between anxiety scores and Skindex scores $(\mathrm{r}=0.29, \mathrm{p}<0.001)$. Other investigators reported similar results (45-47). Though significant, anxiety is found to be contributing to only $8 \%$ of the variance of HRQoL. Further, we tried to assess if different grades of anxiety correspond to similar grades of impairment of HRQoL as reflected in Skindex grades. On the face of it ANOVA gives false impression of correspondence between anxiety and HRQoL scores. This is expected because the scores are correlated. But multiple comparison with Tukey's test of the anxiety scores between normal and mild, mild and moderate and between moderate and severe grades of Skindex revealed no significant difference (Table 3 ).

The prevalence of depression (14\%) in the present study also is less than that reported by Schmit and Ford (48) (31\%), Basher et al (49) (34\%), Sharma et al (50) (46.25\%), Ponarovsky etal (30) (23.1\%), Seyhan etal (8) (32\%), Solgajova et al (51) (37.5\%). Our finding of significant correlation ( $\mathrm{r}$ 0.34, $\mathrm{p}<0.001)$ between depression scores and Skindex scores are similar to other studies (4548). However, depression is seen to be 
contributing to only $11 \%$ of the variance in Skindex-29 scores. ANOVA and posthoc Tukey's test analysis of depression scores of different grades of Skindex scores yielded results similar to anxiety scores (Table 4). It appears depression and anxiety scores cannot serve as anchors to determine grades of severity of impairment of QoL.

\section{Conclusion}

The present study raises the familiar difficulty in interpreting HRQoL scores in patients with skin diseases $(34,52)$. The anchor based categories of Prinsen et al (34) may not serve the purpose in our settings. It also appears that skin diseases have different meanings to Indian patients than what is generally perceived. An anchor-based approach with appropriately worded anchor questions as well as a distribution based method Nijsten et al (53) with an additional normal sample may help in determining the grades of impairment of QoL. The cross sectional nature of the present study does not allow any inferences to be drawn about the responsivity of the scores to treatment. All categories of skin diseases are also not represented in adequate numbers in the present study. More importantly, what are the factors that have unique influence in determining QoL of dermatologically ill in our setting need to be explored fully to enable clinicians to chalk out appropriate strategies collaboratively to deliver comprehensive and holistic care to the clientele.

\section{References}

1. Basra KAM, Shahrukh M (2009). Burden of skin diseases. Expert Rev Pharmacoeconomics Outcomse Res 9(3):271-283.

2. Hay RJ, Johns NE, Williams HC, et al (2014). The global burden of skin diseases in 2010: An analysis of the prevalence and impact of skin conditions. J Invest Dermatol 134:1527-1534.
3. Chren MM, Rebecca LJ, Linda QM, et al (1996). Skindex, a quality-of-life measure for patients with skin diseases: Reliability, validity and responsiveness. $J$ Invest Dermatol 107:707-713.

4. Ghosh S, Behere V Rishikesh, Sharma PVSN, Sreejayan K (2013). Psychiatric evaluation in dermatology: An overview. Indian J Dermatol 58:39-43.

5. Picardi A, Amerio P, Baliva G, et al (2004). Recognition of depressive and anxiety disorders in dermatological out patients. Acta Derm Venereol 84(3): 213-217.

6. Schmid-Ott G, Steen T (2010). Skin Disorders and Quality of Life. In: International Encyclopedia of Rehabilitation. Stone JH and Blovin M eds. http://cirrie.buffalo.edu/ encyclopedia/en/article/152/2010.

7. Sibel M, Altunay IK (2 0006$)$. Psychodermatology : A collaborative subject of psychiatry and dermatology. Turkish JPsychiatry 17(4): 305-313.

8. Seyhan M, Aki T, Karincaoglu Y, Ozcan H (2006). Psychiatric morbidity in dermatology patients: Frequency and results of consultations. Indian $J$ Dermatol 51(1):18-22.

9. Kiec-Swierczynska M, Dudek B, Krecirz $\mathrm{B}$, et al (2006). The role of psychological factors and psychiatric disorders in skin diseases. Med Pr 57(6): 551-555.

10. Shumaker SA, Naughton MJ (1995). The international assessment of health related quality of life. In: The International Assessment of Health Related Quality of Life: Theory, Translation, Measurement and Analysis. Shumaker SA, Berzon RA eds. New York : Rapid Communications, 3-10. 
11. Higaki $\mathrm{Y}$, Kawamoto $\mathrm{K}$, Kamo $\mathrm{T}$, et al (2002). The Japanese version of Skindex16: A brief quality-of-life measure for patients with skin diseases. $J$ Dermatol 29:693-698.

12. Chren MM (2010). Interpretation of quality-of-life scores. $J$ Invest Dermatol 130:1207-1209.

13. Hughes JE, Barraclough BM, Hamblin LG, White JE (1983). Psychiatric symptoms in dermatology patients. $\mathrm{Br} J$ Psychiatry 143:1-54.

14. Picardi A, Abeni D, Melchi CF, et al (2000). Psychiatric morbidity in dermatological outpatients: An issue to be recognized. BrJ Dermatol 143: 983-991.

15. Zachariae R, Zachariae C (2004). Psychiatric symptoms and quality of life of dermatological outpatients and hospitalized dermatological patients. Acta Derm Veneriol 84:205-212.

16. Gupta MA, Gupta AK, Ellis CN, Koblenzer CS (2005). Psychiatric evaluation in dermatology patient's. Dermatologic clinics 23(4) : 591-599.

17. Basavaraj KH, Navya MA, Rashmi R (2010). Relevance of psychiatry in dermatology. Indian J Psychiatry 52(3) : 270-275.

18. Lee YW, Park EJ, Kwon IH, et al (2010). Impact of psoriasis on quality of life. Ann Dermatol 22(4):389-396.

19. Kumar S, Kachhawha D, Das Koolwal GD, et al (2011). Psychiatric morbidity in psoriasis patients : a pilot study. Indian $J$ Dermatol Venereol Leprol 77:625.

20. Mattoo SK, Hande S, Kaur I, et al (2001). Psychiatric morbidity in vitiligo and psoriasis. JDermatol 28(8): 424-432.
21. Marina RM, Desire DM, Miguel SR, et al (2012).Assessment of psychiatric disorders in vitiligo. Considerations for our daily practice. Our Dermatol online 3(1):61-62.

22. Klassen AF, Newton JN, Mallon E (2000). Measuring quality of life in people referred for specialist care of acne: Comparing generic and disease specific measures. J Am Acad Dermatol 43(2):229233.

23. Pruthi GK, Babu N (2012). Physical and psychosocial impact of acne in adult females. Indian J Dermatol 57(1):26-29.

24. Choudhary S, Raju MSVK, Dubey BL (2001). Alopecia Areata : Evaluation using psychological tests and somatic ink blot test. J Pr Psy and Mental Health 8:143-148.

25. Lamieux J, Maunsel E, Provencher (2008). Chemotherapy-induced alopecia and effects on quality of life among woman with breast cancer. Psychooncology 17:317-328.

26. Ujwala PC, Dincy Peter CV, Pulimood SA (2013). Impact of hand eczema severity on quality of life. Indian Dermatol online 4(2):102-105.

27. Joseph GA, Sunder Rao PSS (1999). Impact of leprosy on the quality of life. Bulletin of WHO 77(6):515-517.

28. Sampogna F, Picardi A, Chren MM, et al (2004). Association between poorer quality of life and psychiatric morbidity in patients with different dermatological conditions. Psychosomatic Medicine 66:620-624. 
29. Abolfotouh MA, Al-khowailed MS, Suliman WE, et al (2012). Quality of life in patients with skin diseases in central Saudi Arabia. Int J Gen Medicine 5: 633642.

30. Ponarovsky B, Amital D, Lazarov A, et al (2011). Anxiety and depression in patients with allergic and non-allergic cutaneous disorders. Int $J$ Dermatol 50(10): 1217-1222.

31. Zung WW (1971). A rating instrument for anxiety disorders. Psychosomatics 12:371-379.

32. Zung WW (1972). The depression status inventory : an adjunct to the self-rating depression scale. J Clin Psychol 28:539543.

33. Chren MM, Lasek RJ, Flocke SA, Zyzanski SJ (1997). Improved discriminative and evaluative capability of a refined version of Skindex, a qualityof-life instrument for patients with skin disorders. Arch Dermatol 133(11):14331440.

34. Prinsen Cecilea AC, Lindeboom R, De corti J (2011). Interpretation of skindex 29 scores-cutoffs for mild moderate and severe impairment of health related quality of life. $J$ Invest Dermatol 131:1935-1947.

35. Tan JK, Vassey K, Furg KY (2001). Beliefs and perceptions of patients with acne. JAm Acad Derm 44(3):439-445.

36. Both H, Essink-Bot ML, Busschback J, Nijsten T (2007). Critical review of generic and dermatology-specific healthrelated quality of life instruments. J Invest Dermatol 127:2726-1239.
37. Bae JM, Beoman H, Hong Surlee (2012). Prevalence of common skin diseases and their associated factors among military personnel in Korea-A cross sectional study. JKorean Med Sci 27:1248-1254.

38. Peyri J, Lleonart M (2007). Clinical and therapeutic profile of quality of life of patients with seborrheic dermatitis. Acats Dermosifiliogr 98:476-482.

39. Kopel E, Levi A, Harari M, et al (2013). Effects of dead sea climatotherapy for psoriasis on quality of life. IMAJ 15(2) : 99-102.

40. Kosaraju SKM, Reddy KS, Naresh V, et al (2015). Psychological morbidity among dermatological patients in rural setting. Indian J Dermatol 60(6): 635.

41. Sanclemente G, Burgos C, Nova J, et al (2017). The impact of skin diseases on quality of life : A multicenter study original article. Actas Dermosifiliogr 108(3): 244-252.

42. Jindal KC, Singh GP, Mohan V (2013). Psychiatric morbidity among inmates of leprosy homes. Indian J Psychol Med 35:335-340.

43. Aslam R, Qadir A, Asad F (2007). Psychiatric morbidity in dermatological outpatients : an issue to be recognized. $J$ Pakistan Assoc Dermatologists 17 : 235239.

44. Abebe G, Ayano G, Andargie G, et al (2016). Prevalence and factors associated with anxiety among patients with common skin disease on follow up at Alert Referral Hospital, Addis Ababa, Ethiopia. $J$ Psychiatry 19(3) : 367. 
45. Yazici K, Baz K, Yazici AE, et al (2004). Disease specific quality of life is associated with anxiety and depression in patients with acne. JEADV 18(4) : 435439.

46. Staubach P, Eckhardt-Henn, Dechene M, et al (2006). Quality of life in patients with chronic urticaria in differentially impaired patients and determined by psychiatric morbidity. Br J Dermatology 154(2) : 294298.

47. Deaver DM (2013). Predictors of quality of life in patients with cutaneous $1 \mathrm{y} \mathrm{m} \mathrm{p} \mathrm{h} \mathrm{o} \mathrm{a} \mathrm{.} \mathrm{T} \mathrm{h} \mathrm{e} \mathrm{s}$ s. http://scholarcommons@usf.edu.

48. Schmit JM, Ford DE (2007). Role of depression in quality of life for patients with psoriasis. Dermatology 215(1) : 1727.

49. Basher K, Nasser RD, Rao SU (2010). Depression in adult dermatology patients. JCPSP 20(12) : 811-813.
50. Sharma S, Bassi R, Singh A (2011). A comparative study of depression and anxiety in psoriasis and other skin diseases. J Pakistan Assoc Dermatologists 24(4):235-240.

51. Solgajova A, Sollar T, Vorosova G, et al (2016). The incidence of anxiety, depression and quality of life in patients with dermatological diseases. Cent Eur Nurs Midw 7(3): 467-483.

52. Chren MM (2012). The skindex instruments to measure the effects of skin diseases on quality of life. Dermatol Clin 30(2) : 231-236.

53. Nijsten T, Sampogna F, Abeni D (2009). Categorization of Skindex -29 scores using mixture analysis. Dermatology 218:151-154. 